\title{
Predição da altura total de árvores em plantios de diferentes espécies por meio de redes neurais artificiais
}

\author{
Bráulio Pizziôlo Furtado Campos; Gilson Fernandes da Silva²; Daniel Henrique Breda Binoti; Adriano Ribeiro de Mendonça²; \\ Helio Garcia Leite ${ }^{3}$ \\ ${ }^{1}$ Engenheiro Florestal, Rod. Mal. Rondon, s/n - Zona Rural, CEP 17120-000, Agudos, SP, Brasil \\ ${ }^{2}$ Universidade Federal do Espírito Santo, Av. Governador Lindemberg, 316, Centro, CEP 29550-000, Jerônimo Monteiro, ES, Brasil \\ ${ }^{3}$ Universidade Federal de Viçosa, Avenida Peter Henry Rolfs, s/n, CEP 36570-900, Viçosa, MG, Brasil
}

"Autor correspondente:
danielhbbinoti@gmail.com

Termos para indexação:

Relação hipsométrica

Inventário florestal

Floresta de produção

Index terms:

Hypsometric relation

Forest inventories

Commercial forestry

Histórico do artigo:

Recebido em 09/03/2016

Aprovado em 04/10/2016

Publicado em 30/12/2016

doi: 10.4336/2016.pfb.36.88.1166

\begin{abstract}
Resumo - O objetivo deste trabalho foi analisar a capacidade de uma rede neural artificial (RNA) em estimar a altura total de árvores de duas espécies em diferentes condições de crescimento. Para fins de comparação, também foi ajustado o modelo hipsométrico de Campos, aplicado por estrato, conforme o gênero, espécie, rotação, espaçamento e classe de idade das árvores. A avaliação das redes neurais artificiais e do modelo de Campos foi realizada com base no coeficiente de correlação entre as alturas observadas e estimadas, a raiz quadrada do erro quadrático médio percentual e de análises gráficas. Observou-se que a altura de árvores de diferentes espécies, em distintas condições de crescimento e locais, pode ser estimada utilizando uma única rede neural, com a mesma eficiência e exatidão normalmente obtida com o emprego de equações de regressão.
\end{abstract}

\section{Estimation of total tree height in plantations of different species through artificial neural networks}

\begin{abstract}
The objective of this study was to analyze the ability of an artificial neural network (ANN) to estimate the total height of two tree species in different growing conditions. For comparison purposes, it was also adjusted Campos hypsometric model, applied by stratum as genus, species, rotation, spacing and age classes. The evaluation of artificial neural networks and Campos model was based on the correlation coefficient between the observed and estimated heights, the square root of the mean square percentage error (RMSE) and graphical analysis. The results of this study showed that trees height of different species, in different growing conditions and locations can be estimated using a single neural network with the same efficiency and accuracy usually obtained with regression equations.
\end{abstract}

\section{Introdução}

Na ciência florestal há uma demanda contínua por novas tecnologias em diversas áreas. No setor produtivo, parte desta demanda tecnológica é proveniente da necessidade de estimação de variáveis dendrométricas para a determinação do estoque de madeira atual e futuro (Husch et al., 2003).
Para explorar o recurso florestal madeireiro de maneira eficiente, é necessário o conhecimento sobre o estoque em crescimento e de colheita, que pode ser obtido por meio da medição e estimação de características das árvores e da área na qual elas estão plantadas (Binoti, 2012). Este conhecimento é importante no manejo florestal, uma vez que fornece informações quantitativas sobre a floresta, auxiliando na definição de planos de 
manejo e em análises econômicas de prescrições de manejo (Husch et al., 2003).

Uma característica importante medida nos inventários florestais é a altura total das árvores, uma vez que possui alta correlação com o volume de madeira no fuste. Conforme Leite \& Andrade (2004), a medição da altura das árvores impacta significativamente nos custos do inventário florestal, tornando de grande importância os estudos sobre modelos, procedimentos e equipamentos para esta estimação. Após a medição, modelos de regressão são comumente utilizados para estimar esta variável para árvores não medidas.

Com o passar dos anos, ferramentas de inteligência computacional, como as redes neurais artificiais (RNA), têm sido empregadas na área de inventário florestal em substituição aos modelos de regressão, apresentando muitas vezes superioridade na acurácia das estimativas de variáveis de interesse (Görgens et al., 2009; Silva et al., 2009). Uma RNA é um modelo matemático baseado no funcionamento do sistema nervoso biológico, sendo composta por unidades simples chamadas de neurônios artificiais.

Entre os diversos fatores para o desempenho superior das RNA em relação aos modelos de regressão, Haykin (2001) cita: habilidade de aprender e generalizar, que as tornam capazes de resolver problemas complexos; capacidade de modelar diversas variáveis e suas relações não lineares; capacidade de modelagem com variáveis categóricas (qualitativas), além das numéricas (quantitativas); e analogia neurobiológica.

Diversos estudos foram realizados comprovando a eficiência de RNA para estimar variáveis comumente utilizadas em inventários florestais, como a estimação de altura (Diamantopoulou \& Milios, 2010; Binoti et al., 2013c, 2013b), estimação de volume de árvores (Diamantopoulou, 2006; Görgens et al., 2009, 2014; Silva et al., 2009; Diamantopoulou \& Milios, 2010; Binoti et al., 2014), modelagem do crescimento e da produção em nível de povoamento (Binoti, 2010), modelagem do crescimento e produção de árvores individuais (Guan \& Gertner 1991; Binoti, 2010; Castro et al, 2013; Vieira, 2015), modelagem do crescimento e produção por classe de diâmetro (Leduc et al., 2001; Binoti et al., 2012, 2013a), modelagem do afilamento do fuste (Diamantopoulou, 2005b; Leite et al., 2011) e quantificação de casca (Diamantopoulou, 2005a). No entanto, ainda não se conhece a resposta da aplicação de uma única RNA para a estimação de variáveis dendrométricas de diferentes espécies.

Nesse sentido, o objetivo deste trabalho foi analisar a capacidade de uma única RNA para estimar altura de Eucalyptus spp. e de Pinus spp. em diferentes idades e condições de crescimento.

\section{Material e métodos}

\section{Descrição da área de estudo e coleta de dados}

Os dados utilizados para realização deste estudo foram provenientes de 13.817 árvores, das quais mediuse o diâmetro a 1,30 $\mathrm{m}$ acima do nível do solo (dap) e a altura total $(\mathrm{Ht})$ no inventário florestal contínuo realizado em 2014, em uma fazenda pertencente a uma empresa florestal na região do Triângulo Mineiro, em Minas Gerais. A área total da fazenda é de 22.624 ha, onde são encontrados plantios de pinus e de eucalipto, em diferentes idades, ciclos e espaçamentos de plantio (Tabelas 1 e 2).

Tabela 1. Proporção da área do plantio de acordo com gênero e classe de idade.

\begin{tabular}{|c|c|c|c|c|c|c|c|c|c|}
\hline \multirow{2}{*}{ Gênero } & & \multicolumn{7}{|c|}{ Classe de Idade (anos) } & \multirow{2}{*}{ Total } \\
\hline & & 2 a 3 & 3 a 4 & 4 a 5 & 5 a 6 & 6 a 7 & 7 a 8 & 8 a 9 & \\
\hline \multirow{2}{*}{ Eucalipto } & Área (ha) & 5.117 & 6.679 & 1.839 & 3.104 & 3.319 & 2.092 & & 22.149 \\
\hline & $\%$ do Total & $23 \%$ & $30 \%$ & $8 \%$ & $14 \%$ & $15 \%$ & $9 \%$ & & $98 \%$ \\
\hline \multirow{2}{*}{ Pinus } & Área (ha) & & & & & & 225 & 250 & 475 \\
\hline & $\%$ do Total & & & & & & $1 \%$ & $1 \%$ & $2 \%$ \\
\hline \multirow{2}{*}{ Total } & Área (ha) & 5.117 & 6.679 & 1.839 & 3.104 & 3.319 & 2.318 & 250 & 22.624 \\
\hline & $\%$ do Total & $23 \%$ & $30 \%$ & $8 \%$ & $14 \%$ & $15 \%$ & $10 \%$ & $1 \%$ & $100 \%$ \\
\hline
\end{tabular}


Tabela 2. Frequência observada das alturas medidas de acordo com gênero, espaçamento, rotação e espécie.

\begin{tabular}{|c|c|c|c|c|}
\hline Gênero & $\begin{array}{c}\text { Espaçamento } \\
\text { (m) }\end{array}$ & Rotação & Espécie & $\begin{array}{c}\mathrm{N}^{0} \text { de alturas } \\
\text { medidas }\end{array}$ \\
\hline \multirow{10}{*}{ EUC } & \multirow{2}{*}{$2,80 \times 3,20$} & \multirow{2}{*}{1} & E & 3.987 \\
\hline & & & EGR & 150 \\
\hline & \multirow{3}{*}{$3,00 \times 1,90$} & \multirow{3}{*}{1} & HGU & 1.896 \\
\hline & & & E & 3.289 \\
\hline & & & EGR & 40 \\
\hline & \multirow{3}{*}{$3,00 \times 2,00$} & \multirow{3}{*}{1} & HGU & 2.736 \\
\hline & & & E & 400 \\
\hline & & & $\mathrm{HGU}$ & 945 \\
\hline & \multirow{2}{*}{$3,00 \times 3,00$} & \multirow{2}{*}{2} & E & 100 \\
\hline & & & $\mathrm{HGU}$ & 15 \\
\hline \multirow{2}{*}{ PIN } & \multirow{2}{*}{$2,80 \times 2,15$} & \multirow{2}{*}{1} & $\mathrm{PCH}$ & 180 \\
\hline & & & POO & 79 \\
\hline & Total & & & 13.817 \\
\hline
\end{tabular}

Em que: $\mathrm{E}=$ Eucalyptus spp., $\mathrm{EGR}=$ Eucalyptus grandis, $\mathrm{HGU}=$ Híbrido Eucalyptus grandis $\mathrm{x}$ Eucalyptus urophylla, $\mathrm{PCH}=$ Pinus caribaea var. hondurensis e $\mathrm{POO}=$ Pinus oocarpa.

Para o ajuste dos modelos hipsométricos empregouse a estratificação normalmente utilizada na empresa (Tabela 3). A distribuição de frequência dos dados por classe de altura e diâmetro utilizados para treinamento das redes neurais artificiais (RNA) (Tabela 3) e ajuste do modelo hipsométrico é apresentada na Tabela 4. As dispersões de Ht em relação ao dap, para cada gênero, são apresentadas na Figura 1. Na Tabela 5 é apresentada a distribuição de alturas e diâmetros para os dados utilizados.

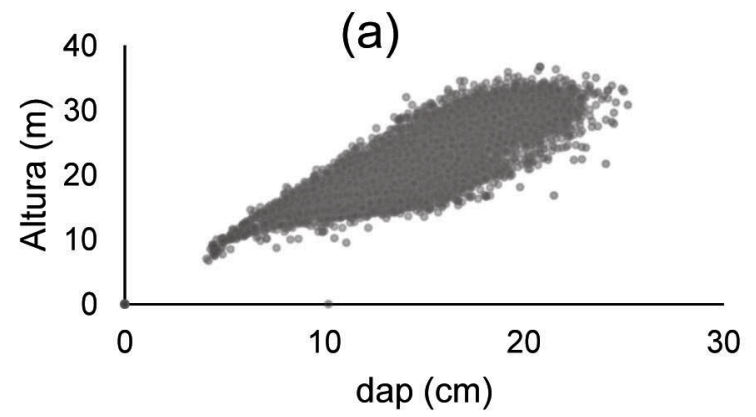

Tabela 3. Estratificação da base de dados de inventário comumente utilizada na empresa.

\begin{tabular}{|c|c|c|c|c|c|}
\hline Estrato & Rotação & Idade & $\begin{array}{c}\text { Espaçamento } \\
(\mathrm{m})\end{array}$ & Gênero & Espécie \\
\hline \multirow{2}{*}{1} & \multirow{2}{*}{1} & $2-3$ & $3,00 \times 1,90$ & Eucalyptus & $\mathrm{E}$ \\
\hline & & $4-5$ & $2,80 \times 3,20$ & Eucalyptus & $\mathrm{E}$ \\
\hline \multirow{2}{*}{2} & \multirow{2}{*}{1} & $3-4$ & $3,00 \times 1,90$ & Eucalyptus & E \\
\hline & & $5-6$ & $2,80 \times 3,20$ & Eucalyptus & $\mathrm{E}$ \\
\hline \multirow{2}{*}{3} & \multirow{2}{*}{1} & $3-4$ & $3,00 \times 2,00$ & Eucalyptus & E \\
\hline & & $6-7$ & $2,80 \times 3,20$ & Eucalyptus & E \\
\hline \multirow{2}{*}{4} & \multirow{2}{*}{1} & $4-5$ & $3,00 \times 2,00$ & Eucalyptus & E \\
\hline & & $7-8$ & $2,80 \times 3,20$ & Eucalyptus & E \\
\hline 5 & 1 & $6-7$ & $2,80 \times 3,20$ & Eucalyptus & EGR \\
\hline \multirow{2}{*}{6} & \multirow{2}{*}{1} & $2-3$ & $3,00 \times 1,90$ & Eucalyptus & HGU \\
\hline & & $4-5$ & $2,80 \times 3,20$ & Eucalyptus & $\mathrm{HGU}$ \\
\hline \multirow{2}{*}{7} & \multirow{2}{*}{1} & $3-4$ & $3,00 \times 1,90$ & Eucalyptus & $\mathrm{HGU}$ \\
\hline & & $5-6$ & $2,80 \times 3,20$ & Eucalyptus & $\mathrm{HGU}$ \\
\hline \multirow{2}{*}{8} & \multirow{2}{*}{1} & $3-4$ & $3,00 \times 2,00$ & Eucalyptus & $\mathrm{HGU}$ \\
\hline & & $6-7$ & $2,80 \times 3 z, 20$ & Eucalyptus & $\mathrm{HGU}$ \\
\hline \multirow{2}{*}{9} & \multirow{2}{*}{1} & $4-5$ & $3,00 \times 2,00$ & Eucalyptus & $\mathrm{HGU}$ \\
\hline & & $7-8$ & $2,80 \times 3,20$ & Eucalyptus & $\mathrm{HGU}$ \\
\hline 10 & 1 & $4-5$ & $2,80 \times 3,20$ & Eucalyptus & $\mathrm{E}$ \\
\hline \multirow{2}{*}{11} & \multirow{2}{*}{2} & $3-4$ & $3,00 \times 3,00$ & Eucalyptus & $\mathrm{E}$ \\
\hline & & $3-4$ & $3,00 \times 3,00$ & Eucalyptus & $\mathrm{HGU}$ \\
\hline 12 & 1 & $2-3$ & $3,00 \times 1,90$ & Eucalyptus & EGR \\
\hline \multirow{2}{*}{13} & \multirow{2}{*}{1} & $7-8$ & $2,80 \times 2,15$ & Pinus & $\mathrm{PCH}$ \\
\hline & & $8-9$ & $2,80 \times 2,15$ & Pinus & $\mathrm{PCH}$ \\
\hline \multirow{2}{*}{14} & \multirow{2}{*}{1} & $7-8$ & $2,80 \times 2,15$ & Pinus & POO \\
\hline & & $8-9$ & $2,80 \times 2,15$ & Pinus & $\mathrm{POO}$ \\
\hline
\end{tabular}

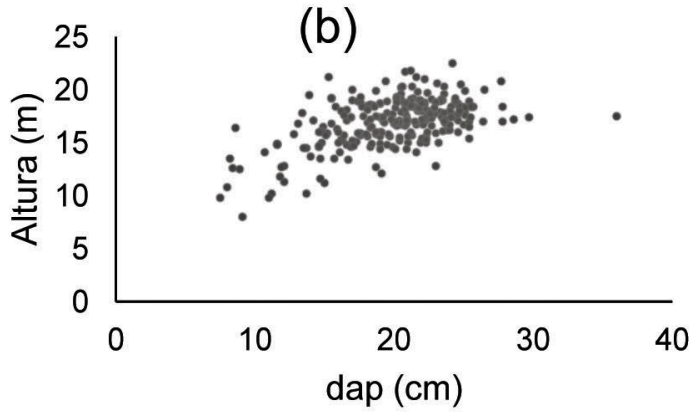

Figura 1. Dispersão das alturas totais em relação ao dap nos povoamentos de eucaliptos (a) e pinus (b). 
Tabela 4. Estatísticas descritivas das variáveis contínuas amostradas por estrato.

\begin{tabular}{|c|c|c|c|c|c|c|c|c|c|c|c|c|}
\hline \multirow[b]{2}{*}{ Variável } & \multirow[b]{2}{*}{ Estrato } & \multicolumn{5}{|c|}{ Estatísticas descritivas } & \multirow[b]{2}{*}{ Estrato } & \multicolumn{5}{|c|}{ Estatísticas descritivas } \\
\hline & & Mínimo & Máximo & Média & Mediana & $\begin{array}{l}\text { Desv. } \\
\text { Pad. }\end{array}$ & & Mínimo & Máximo & Média & Mediana & $\begin{array}{l}\text { Desv. } \\
\text { Pad. }\end{array}$ \\
\hline Idade (meses) & \multirow{4}{*}{1} & 27,9 & 60,0 & 34,9 & 31,0 & 10,0 & \multirow{4}{*}{8} & 42,2 & 83,2 & 63,1 & 73,3 & 16,3 \\
\hline dap $(\mathrm{cm})$ & & 4,4 & 24,5 & 13,1 & 12,9 & 2,9 & & 4,6 & 24,0 & 16,5 & 16,7 & 3,0 \\
\hline $\mathrm{Ht}(\mathrm{m})$ & & 7,5 & 31,1 & 17,6 & 16,5 & 4,1 & & 8,2 & 34,7 & 25,5 & 26,3 & 4,6 \\
\hline $\mathrm{HD}(\mathrm{m})$ & & 15,1 & 29,0 & 18,6 & 17,1 & 3,8 & & 19,6 & 34,0 & 26,0 & 27,3 & 4,2 \\
\hline Idade (meses) & \multirow{4}{*}{2} & 36,9 & 74,6 & 55,3 & 49,2 & 13,8 & \multirow{4}{*}{9} & 50,1 & 96,4 & 73,4 & 84,8 & 19,2 \\
\hline dap $(\mathrm{cm})$ & & 4,2 & 23,4 & 15,8 & 16,1 & 3,0 & & 4,5 & 24,9 & 17,0 & 17,7 & 3,5 \\
\hline $\mathrm{Ht}(\mathrm{m})$ & & 6,7 & 33,5 & 23,0 & 23,0 & 4,4 & & 7,5 & 33,8 & 26,2 & 27,6 & 5,0 \\
\hline $\mathrm{HD}(\mathrm{m})$ & & 16,4 & 31,9 & 23,8 & 24,0 & 4,2 & & 21,4 & 33,1 & 27,2 & 29,0 & 3,9 \\
\hline Idade (meses) & \multirow{4}{*}{3} & 42,6 & 87,6 & 75,4 & 78,3 & 11,5 & \multirow{4}{*}{10} & 57,3 & 65,0 & 60,6 & 57,3 & 3,6 \\
\hline dap $(\mathrm{cm})$ & & 7,0 & 24,4 & 18,1 & 18,6 & 2,7 & & 7,3 & 23,7 & 17,2 & 17,8 & 3,6 \\
\hline $\mathrm{Ht}(\mathrm{m})$ & & 13,0 & 33,2 & 27,4 & 28,1 & 3,3 & & 13,0 & 28,0 & 22,9 & 23,2 & 3,2 \\
\hline $\mathrm{HD}(\mathrm{m})$ & & 20,4 & 32,2 & 28,3 & 29,1 & 2,9 & & 21,4 & 27,4 & 24,4 & 25,5 & 2,3 \\
\hline Idade (meses) & \multirow{4}{*}{4} & 49,7 & 96,6 & 81,7 & 89,2 & 16,4 & \multirow{4}{*}{11} & 40,5 & 42,8 & 41,9 & 41,8 & 0,7 \\
\hline dap (cm) & & 4,6 & 25,2 & 17,4 & 17,8 & 3,1 & & 6,0 & 18,0 & 13,4 & 13,8 & 2,1 \\
\hline $\mathrm{Ht}(\mathrm{m})$ & & 8,6 & 36,7 & 27,4 & 28,4 & 4,3 & & 12,3 & 24,5 & 20,3 & 20,5 & 2,1 \\
\hline $\mathrm{HD}(\mathrm{m})$ & & 20,1 & 34,1 & 28,4 & 29,6 & 3,5 & & 19,6 & 22,6 & 21,1 & 21,0 & 0,9 \\
\hline Idade (meses) & \multirow{4}{*}{5} & 63,6 & 87,2 & 78,4 & 83,6 & 8,8 & \multirow{4}{*}{12} & 31,7 & 31,9 & 31,8 & 31,8 & 0,1 \\
\hline dap (cm) & & 11,6 & 24,4 & 17,7 & 17,7 & 2,7 & & 4,5 & 16,2 & 11,15 & 11,1 & 2,6 \\
\hline $\mathrm{Ht}(\mathrm{m})$ & & 17,6 & 33,8 & 25,6 & 25,9 & 2,9 & & 8,2 & 19,8 & 14,6 & 14,9 & 2,8 \\
\hline $\mathrm{HD}(\mathrm{m})$ & & 22,1 & 30,7 & 26,6 & 26,9 & 2,2 & & 13,9 & 16,7 & 15,3 & 15,3 & 1,4 \\
\hline Idade (meses) & \multirow{4}{*}{6} & 27,8 & 59,9 & 34,5 & 33,4 & 7,3 & \multirow{4}{*}{13} & 89,0 & 102,4 & 96,8 & 95,2 & 4,3 \\
\hline dap (cm) & & 4,3 & 21,8 & 13,2 & 13,1 & 2,2 & & 7,5 & 36,0 & 20,3 & 20,9 & 4,2 \\
\hline $\mathrm{Ht}(\mathrm{m})$ & & 8,5 & 32,0 & 17,9 & 17,4 & 3,3 & & 8,0 & 22,5 & 16,6 & 17,0 & 2,1 \\
\hline $\mathrm{HD}(\mathrm{m})$ & & 12,6 & 28,9 & 18,4 & 17,7 & 3,0 & & 15,0 & 19,0 & 17,4 & 17,5 & 0,9 \\
\hline Idade (meses) & \multirow{4}{*}{7} & 37,1 & 77,2 & 49,3 & 45,7 & 10,8 & \multirow{4}{*}{14} & 90,8 & 104,9 & 101,7 & 104,9 & 5,6 \\
\hline dap (cm) & & 4,1 & 23,4 & 14,6 & 14,5 & 3,0 & & 8,0 & 27,7 & 19,0 & 19,6 & 4,1 \\
\hline $\mathrm{Ht}(\mathrm{m})$ & & 7,0 & 33,1 & 21,7 & 20,7 & 4,3 & & 10,2 & 21,8 & 17,7 & 18,4 & 2,5 \\
\hline $\mathrm{HD}(\mathrm{m})$ & & 15,1 & 31,2 & 22,3 & 21,2 & 3,9 & & 15,2 & 19,6 & 18,6 & 18,9 & 1,2 \\
\hline
\end{tabular}

Em que: dap = diâmetro medido a 1,30 m de altura; $\mathrm{N}$ = número de árvores por ha; $\mathrm{Ht}=$ altura total das árvores e; $\mathrm{HD}=$ altura média das árvores dominantes.

Tabela 5. Frequência observada das árvores por classe de altura (Ht) e por classe de diâmetro (dap).

\begin{tabular}{|c|c|c|c|c|c|c|c|}
\hline \multirow{2}{*}{$\begin{array}{l}\text { Classe dap } \\
\quad(\mathrm{cm})\end{array}$} & \multicolumn{6}{|c|}{ Classe Ht (m) } & \multirow{2}{*}{ Total } \\
\hline & $6,1-12,1$ & $12,1-18,1$ & $18,1-24,1$ & $24,1-30,1$ & $30,1-36,1$ & $36,1-42,1$ & \\
\hline $4-8$ & 104 & 117 & & & & & 221 \\
\hline $8,1-12$ & 22 & 1.423 & 474 & 4 & & & 1.923 \\
\hline $12,1-16$ & 5 & 1.682 & 2.971 & 602 & 13 & & 5.273 \\
\hline $16,1-20$ & & 108 & 815 & 3.422 & 612 & & 4.957 \\
\hline $20,1-24$ & & 60 & 78 & 702 & 545 & 4 & $1.38 \mathrm{~s}$ \\
\hline $24,1-28$ & & 19 & 19 & 4 & 9 & & 51 \\
\hline $28,1-32$ & & 2 & & & & & 2 \\
\hline $32,1-36$ & & 1 & & & & & 1 \\
\hline Total & 131 & 3.412 & 4.357 & 4.734 & 1.179 & 4 & 13.817 \\
\hline
\end{tabular}




\section{Treinamento das redes neurais artificiais}

O treinamento da RNA foi realizado visando estimar a altura total das árvores, utilizando informações comumente coletadas em inventário de florestas comerciais. Foram consideradas como entrada para treinamento da RNA as seguintes variáveis qualitativas: gênero (eucalipto e pinus), espécie ( $\mathrm{E}=$ Eucalyptus spp., $\mathrm{EGR}=$ Eucalyptus grandis, $\mathrm{HGU}=$ Híbrido Eucalyptus grandis $\mathrm{x}$ Eucalyptus urophylla, $\mathrm{PCH}=$ Pinus caribaea var. hondurensis e $\mathrm{POO}=$ Pinus oocarpa. $)$ e rotação $\left(1^{\mathrm{a}}\right.$ e $2^{\mathrm{a}}$ ). E como variáveis contínuas: diâmetro com casca medido a 1,30 m de altura da superfície do solo (dap, em $\mathrm{cm}$ ), altura dominante média da parcela $(\mathrm{m})$, idade (meses) e número de árvores por ha, totalizando quatro variáveis contínuas. A saída da rede foi a altura total das árvores medidas (m). As estatísticas descritivas das variáveis quantitativas são apresentadas na Tabela 4 . As variáveis contínuas foram normalizadas linearmente no intervalo de 0 a 1 , e as variáveis categóricas foram normalizadas utilizando a metodologia 1-de-N (Goldschmidt \& Passos, 2005; Heaton, 2011).

O número de neurônios na camada de entrada variou de acordo com as variáveis consideradas. O número de neurônios na camada oculta variou entre 4 e 16 (com incremento a cada dois neurônios). A camada de saída foi constituída por um neurônio, sendo este referente à altura total da árvore. Como funções de ativação da camada oculta e de saída, foram testadas as funções tangente hiperbólica, logística e sigmoide (Braga et al., 2007).

As redes neurais artificiais testadas foram do tipo Multilayer Perceptron (MLP), e os algoritmos de treinamento testados foram o error backpropagation $\mathrm{e}$ o resilient propagation (Haykin, 2001).

Para o algoritmo error backpropagation foram testadas variações no valor da taxa de aprendizado e no parâmetro momentum, variando ambos para os valores de $0,001,0,0005$ e 0,0001 . Além das variações testadas, foram analisadas as estratégias de autoajuste destes parâmetros, em que o processo reduz os valores dos parâmetros ao longo da evolução do algoritmo. Para o algoritmo resilient propagation foi utilizada a variação RPROP+ (Heaton, 2011). Como critérios de parada dos treinamentos das RNA, foi utilizado o número total de 30.000 ciclos ou o erro quadrático médio inferior a $0,1 \%$.

Os pesos iniciais de todas as redes foram gerados de forma aleatória. Para cada combinação avaliada foram treinadas cinco redes, sendo selecionada a melhor destas para posterior comparação entre as combinações. Para treinamento e aplicação das RNA foi utilizado o sistema livre NeuroForest 3.0 (http://neuroforest.ucoz.com/).

Para efeito de comparação, foram utilizados modelos hipsométricos comumente empregados pelas empresas brasileiras para estimação da altura em plantios comerciais (Equações 1 a 3). Cada modelo foi ajustado por estrato, definidos pelo gênero, espécie, rotação, espaçamento e classe de idade (Tabela 5).

a) Campos et al. (1984)

$$
H t_{i}=\exp \left[\beta_{0}+\beta_{1}\left(\operatorname{dap}_{i}\right)^{-1}+\beta_{2} \operatorname{Ln}\left(H d_{i}\right)\right]+\varepsilon_{i}
$$

b) Curtis (1967)

$$
H t_{i}=\beta_{0} \exp \left(\frac{\beta_{1}}{\text { dap }_{i}}\right)+\varepsilon_{i}
$$

c) Prodan (1968)

$$
H t_{i}-1,30=\frac{\operatorname{dap}_{i}^{2}}{\beta_{0}+\beta_{1} d a p_{i}+\beta_{2} \operatorname{dap}_{i}^{2}}+\varepsilon_{i}
$$

em que: $H t=$ altura total da árvore $(\mathrm{m}) ; H d=$ altura dominante da parcela $(\mathrm{m})$; dap = diâmetro medido a $1,30 \mathrm{~m}$ de altura da superfície do solo $(\mathrm{cm}) ;$ e $\mathrm{Ln}=$ logaritmo neperiano.

A avaliação das estimativas foi feita com base no coeficiente de correlação entre as alturas observadas e estimadas $\left(\boldsymbol{r}_{\hat{y} \boldsymbol{y}}\right)$, na raiz quadrada do erro quadrático médio (RMSE), por meio da análise visual dos resíduos e pela observação do histograma de frequência de resíduos. Foi escolhida a RNA que apresentou maior coeficiente de correlação e menor RMSE, e gráficos de dispersão dos resíduos e histogramas sem tendenciosidade, com maior ocorrência de observações em torno de zero.

$$
\operatorname{erro}(\%)=\frac{\hat{Y}_{i}-Y_{i}}{Y_{i}} \cdot 100
$$

em que: $Y$ : altura total observada e; $\hat{Y}$ : altura total estimada.

$$
r_{\hat{y} y}=\frac{\operatorname{cov}(\hat{y}, y)}{\sqrt{S^{2}(\hat{y}) S^{2}(y)}}
$$

em que: $\mathrm{s}^{2}$ : variância e cov: covariância.

$$
\operatorname{RMSE}(\%)=\frac{100}{Y} \sqrt{\frac{\sum_{i=1}^{n}\left(Y_{i}-\hat{Y}_{i}\right)^{2}}{n}}
$$

em que: $Y=$ altura total observada; $\bar{Y}=$ altura total estimada; $\bar{Y}=$ média das alturas totais observadas; e $n$ $=$ número total de observações. 


\section{Resultados e discussão}

Foram obtidas 14 equações para cada modelo hipsométrico, sendo realizada a análise visual dos gráficos de dispersão dos resíduos e histograma de frequência dos resíduos, onde o modelo de Campos foi indicado como o de melhor desempenho em estimar as alturas, sendo as suas estimativas comparadas com as obtidas pelas RNA (Tabelas 6 a 8).

O modelo de Campos foi acurado em estimar as alturas para os povoamentos de pinus e de eucaliptos $\left(\boldsymbol{r}_{\hat{y} y}\right.$ $=97,57 \%$ e RMSE $=5,30 \%$ ), com gráfico de dispersão dos resíduos com ligeira tendência em superestimar alturas para diâmetros menores que $10 \mathrm{~cm}$, sendo este resultado corroborado pelo encontrado no histograma de frequência dos resíduos. Observaram-se, também, as maiores ocorrências em torno de zero, com $85 \%$ das frequências entre $-5 \%$ e $5 \%$. Ao analisar os resultados obtidos por estrato, notam-se altos coeficientes de correlação para a maioria dos estratos, com resíduos distribuídos de forma homogênea e histograma de frequência apresentando tendência de distribuição normal. Para o estrato $12\left(\boldsymbol{r}_{\hat{y} \boldsymbol{y}}=75,1 \%\right.$ e RMSE $=$ $10,7 \%$ ), observou-se acurácia inferior à encontrada para os demais estratos.

Tabela 6. Parâmetros das equações do modelo de Campos ajustadas para cada estrato.

\begin{tabular}{cccc}
\hline \multirow{2}{*}{ Estratos } & \multicolumn{3}{c}{ Estimativas dos Parâmetros } \\
\cline { 2 - 4 } 1 & $\mathbf{B}_{\mathbf{0}}$ & $\mathbf{B}_{1}$ & $\mathbf{B}_{2}$ \\
\hline 2 & 0,7482 & $-3,9059$ & 0,8337 \\
3 & 0,9809 & $-4,7197$ & 0,7765 \\
4 & 1,1666 & $-5,8470$ & 0,7397 \\
5 & 1,1165 & $-5,4218$ & 0,7517 \\
6 & 0,5857 & $-5,6584$ & 0,9094 \\
7 & 0,5533 & $-3,4981$ & 0,8937 \\
8 & 1,0231 & $-4,5909$ & 0,7657 \\
9 & 1,1369 & $-5,0940$ & 0,7418 \\
10 & 1,0200 & $-5,7089$ & 0,7850 \\
11 & 0,7000 & $-5,5196$ & 0,8664 \\
12 & 2,1020 & $-4,9011$ & 0,4222 \\
13 & 1,9414 & $-5,1196$ & 0,4471 \\
14 & 0,7257 & $-5,2078$ & 0,8230 \\
\hline
\end{tabular}

Tabela 7. Estatísticas dos ajustes do modelo de Campos e da melhor RNA, por estrato.

\begin{tabular}{|c|c|c|c|c|c|c|c|c|c|c|c|c|c|c|c|}
\hline \multirow{2}{*}{\multicolumn{2}{|c|}{ Estatísticas }} & \multicolumn{14}{|c|}{ Estratos } \\
\hline & & 1 & 2 & 3 & 4 & 5 & 6 & 7 & 8 & 9 & 10 & 11 & 12 & 13 & 14 \\
\hline \multirow{2}{*}{ Campos } & $\mathbf{r}_{\overline{y y}}$ & 97,6 & 96,5 & 94,3 & 93,2 & 86,5 & 96,2 & 95,5 & 95,6 & 96,6 & 92,4 & 80,9 & 75,1 & 70,2 & 79,4 \\
\hline & RMSE & 5,0 & 6,5 & 6,1 & 8,7 & 8,3 & 5,5 & 7,2 & 7,6 & 7,2 & 6,9 & 7,1 & 10,7 & 8,4 & 8,6 \\
\hline \multirow{2}{*}{ RNA } & $\mathbf{r}_{\overline{y y}}$ & 97,5 & 96,7 & 94,8 & 93,4 & 87,0 & 96,4 & 95,6 & 95,9 & 97,1 & 92,4 & 83,2 & 75,8 & 71,7 & 80,3 \\
\hline & RMSE & 5,1 & 6,3 & 5,8 & 8,5 & 8,1 & 5,4 & 7,1 & 7,4 & 6,7 & 6,9 & 6,7 & 10,6 & 8,2 & 8,4 \\
\hline
\end{tabular}

Para se comparar os resultados encontrados pelo ajuste do modelo de Campos com os encontrados empregandose RNA, foi selecionada uma RNA levando-se em conta análises gráficas e coeficientes estatísticos. A RNA selecionada apresenta quatro neurônios na camada oculta, encontrando-se, para ela, valores de $\boldsymbol{r}_{\hat{y} y}$ de $97,7 \%$ e $\mathrm{RMSE}=5,16 \%$. Pela análise do gráfico de dispersão dos resíduos é possível notar menor amplitude de dispersão dos resíduos e maiores ocorrências em torno de zero, quando comparado aos gráficos do modelo de Campos, com $87 \%$ das frequências ocorrendo entre $-5 \%$ e $5 \%$. Os resultados obtidos por estrato apresentam altos coeficientes de correlação para a maioria dos estratos, com resíduos distribuídos de forma homogênea e histograma de frequência apresentando tendência de distribuição normal. Para o estrato 12 , encontrou-se $\boldsymbol{r}_{\hat{y} \boldsymbol{y}}=$ $75,8 \%$ e RMSE $=10,6 \%$, ou seja, houve um desempenho inferior do processo de estimação para este estrato, em termos de acurácia, quando comparado aos demais estratos, semelhante ao que ocorreu com o modelo de Campos nesse mesmo estrato. Este resultado pode ser explicado pelo tamanho reduzido da área de plantio do estrato 12, isto é, apenas 85 ha, o que levou a uma amostragem menos intensa daquele estrato, impedindo que a tendência de crescimento fosse melhor captada. 


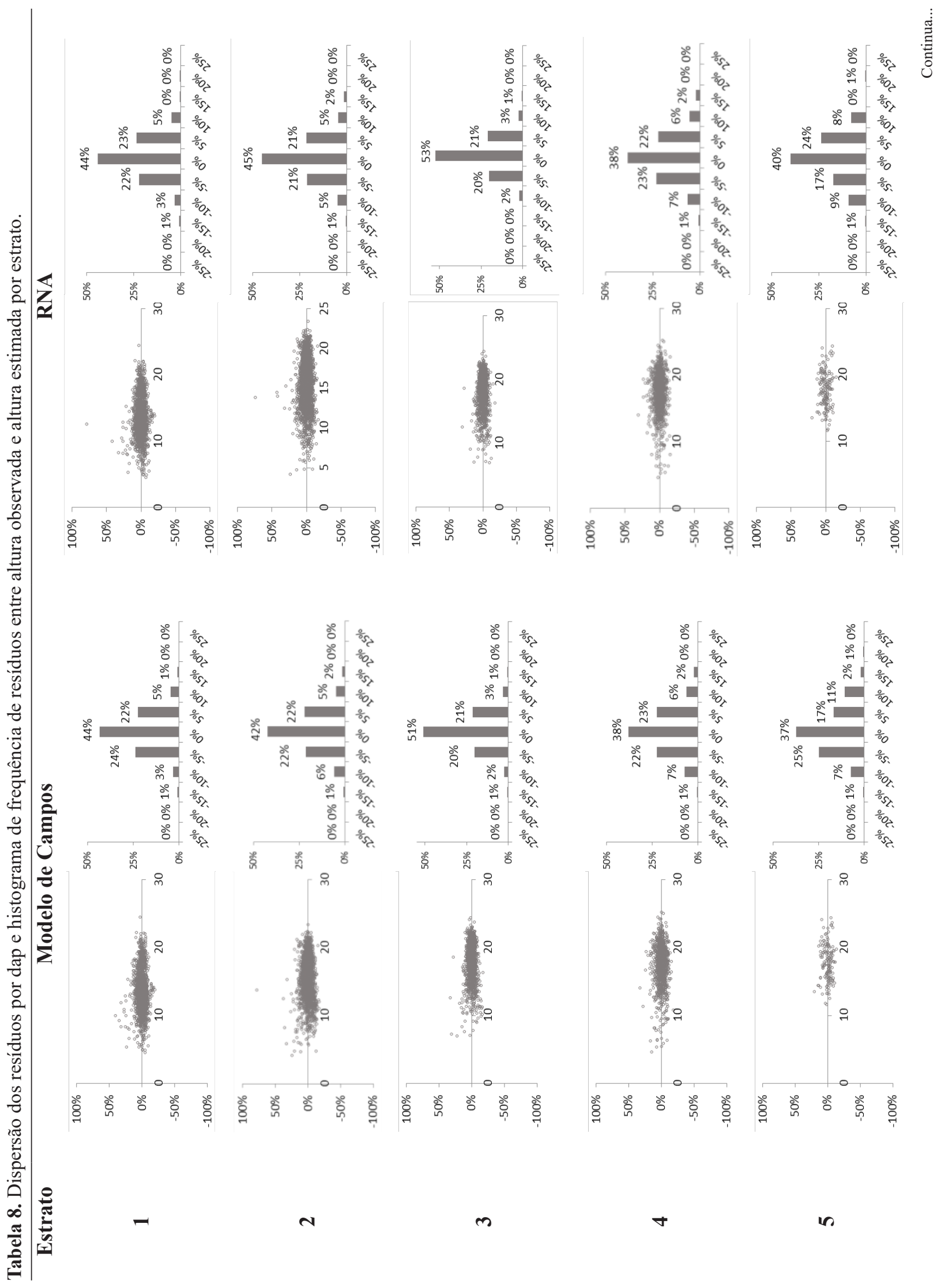

Pesq. flor. bras., Colombo, v. 36, n. 88, p. 375-385, out./dez. 2016 


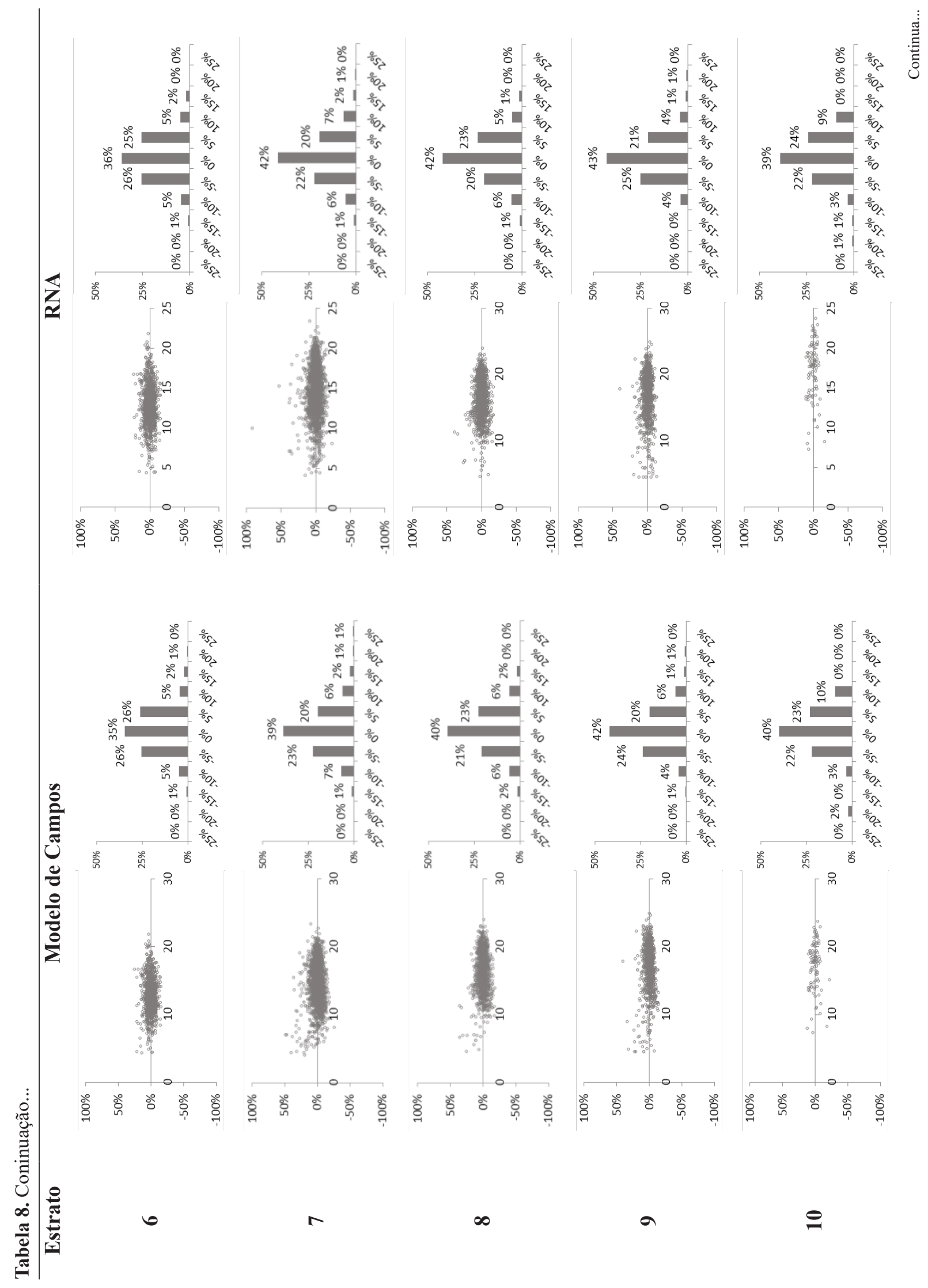




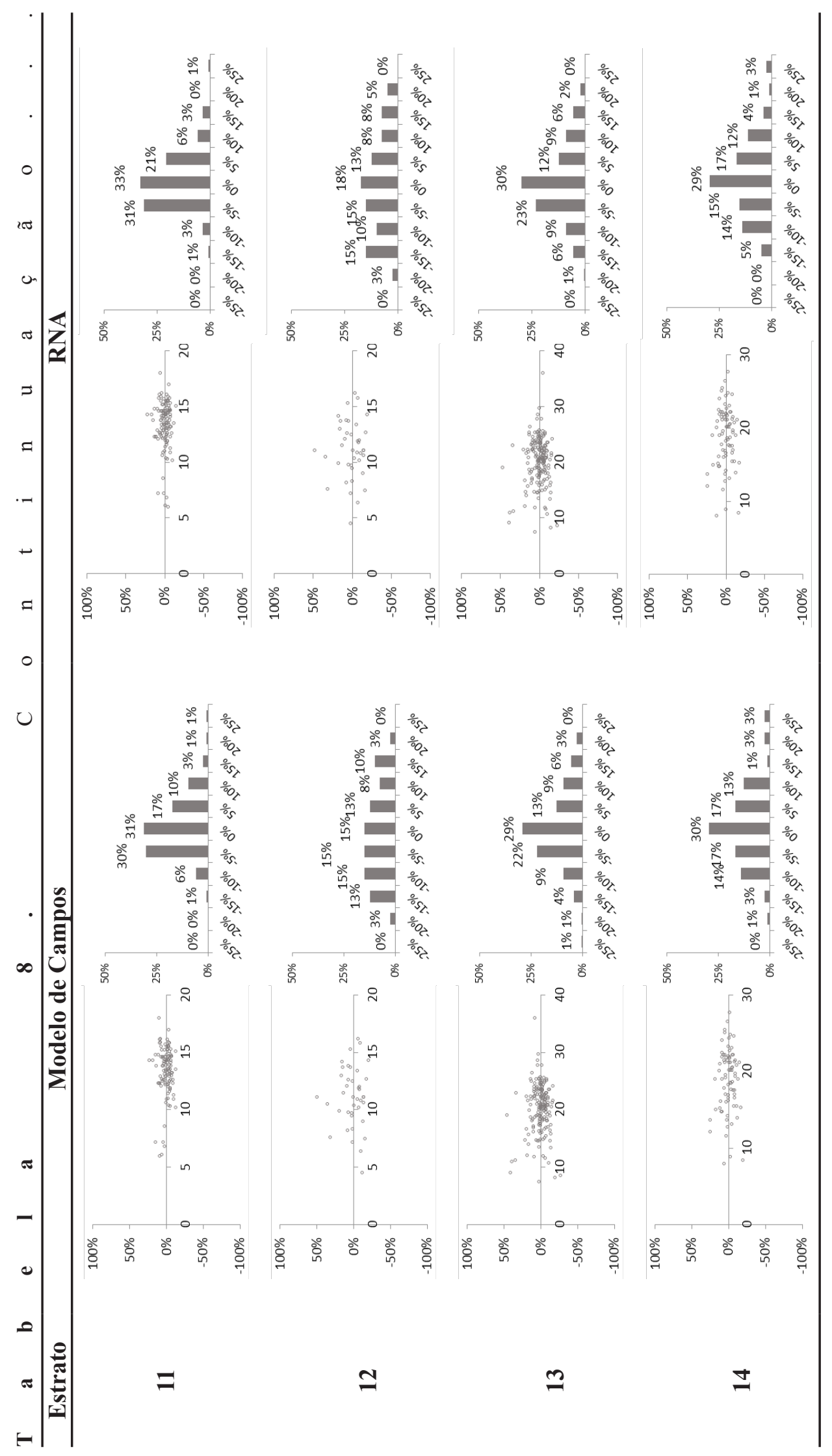


Resultados satisfatórios foram encontrados com configurações de apenas 3 ou 4 neurônios na camada oculta, evidenciando que não são necessárias estruturas complexas para estimação da altura de árvores. Provavelmente esta resposta pode estar ligada ao fato de o número de neurônios na camada oculta representar a não linearidade entre os dados (Braga et al., 2007; Binoti, 2012) e, para este caso, não houve necessidade de grande complexidade da estrutura da rede para captar a tendência de crescimento. De acordo com Braga et al. (2007) e Bullinaria (2010) recomendamse configurações mais simples para essa aplicação das RNA, evitando ocorrência de overfitting e facilitando o processo de busca e otimização da configuração para determinada tarefa.

Embora o algoritmo error backpropagation tenha mostrado resultados satisfatórios, o algoritmo Resillient propagation resultou em melhor desempenho ao estimar a altura de árvores de pinus e eucalipto. As três funções de ativação testadas (tangente hiperbólica, logística e sigmoidal), apresentaram resultados satisfatórios para estimação de altura, tanto na camada oculta quanto na camada de saída. Os valores de taxa de aprendizado e momentum testados para o algoritmo error backpropagation não influenciaram no tempo de treinamento da RNA.

Pode-se observar pouca diferença na acurácia das estimativas obtidas pela equação de regressão e a obtida pela RNA. É importante destacar que as estimativas produzidas pelo modelo de Campos foram obtidas a partir de 14 equações hipsométricas, sendo uma para cada estrato proposto. Esta estratificação requer maior quantidade de unidades de amostra para cada estrato a fim de se obter ajustes satisfatórios das equações, o que nem sempre ocorre. Observando a Tabela 3, nota-se a união de estratos mais homogêneos a fim de se obter intensidade amostral adequada para ajuste.

Nesse estudo não foi considerada a possibilidade de redução do número de árvores, uma vez que isto já foi verificado por Binoti et al. (2013c). Estes autores obtiveram maior exatidão nas estimativas de altura de árvores ao empregarem RNA e concluíram que as redes foram eficientes para alcançar os objetivos propostos, garantindo exatidão das estimativas para clones recémintroduzidos no povoamento, dos quais não se conhecia a relação hipsométrica.

\section{Conclusão}

A altura de árvores de diferentes espécies, em distintas condições de crescimento e locais, pode ser estimada utilizando uma única rede neural com a mesma eficiência e exatidão normalmente obtida com o emprego de equações de regressão.

\section{Referências}

Binoti, D. H. B. et al. Configuração de redes neurais artificiais para estimação do volume de árvores. Ciência da Madeira, v. 5, n. 1, p. $58-67,2014$

Binoti, D. H. B. et al. Modelagem da distribuição de diâmetros utilizando autômatos celulares e redes neurais artificiais. Cerne, v. 19, n. 4, p. 677-685, 2013a. DOI: 10.1590/S010477602013000400019 .

Binoti, D. H. B. et al. Modelagem da distribuição diamétrica em povoamentos de eucalipto submetidos a desbaste utilizando autômatos celulares. Revista Árvore, v. 36, n. 5, p. 931-940, 2012. DOI: $10.1590 / \mathrm{S} 0100-67622012000500015$.

Binoti, D. H. B. et al. Redução dos custos em inventário de povoamentos equiâneos. Agrária: Revista Brasileira de Ciências Agrárias, v. 8, n. 1, p. 125-129, 2013b. DOI: 10.5039/agraria. v8i1a2209.

Binoti, M. L. M. da S. Redes neurais artificiais para prognose da produção de povoamentos não desbastados de eucalipto. 2010 . 54 f. Dissertação (Mestrado em Ciência Florestal) - Universidade Federal de Viçosa, Viçosa, MG.

Binoti, M. L. M. S. et al. Aplicação de redes neurais artificiais para estimação da altura de povoamentos equiâneos de eucalipto. Revista Árvore, v. 37, n. 4, p. 639-645, 2013c. DOI: 10.1590/ S0100-67622013000400007.

Binoti, M. L. M. S. Emprego de redes neurais artificiais em mensuração e manejo florestal. 2012. 130 f. Tese (Doutorado em Ciência Florestal) - Universidade Federal de Viçosa, Viçosa, MG.

Braga, A. P. et al. Redes neurais artificiais: teoria e aplicação. Rio de Janeiro: LTC, 2007. 262 p.

Bullinaria, J. A. Introduction to neural computation. Notas de aula. Disponível em: <http://www.cs.bham.ac.uk/ jxb/inc.html >. Acesso em: 15 nov. 2010.

Campos, J. C. C. et al. Inventário florestal nacional: reflorestamento: Minas Gerais. Brasília, DF: IBDF, 1984. 126 p.

Castro, R. V. O. et al. Individual growth model for Eucalyptus stands in Brazil using artificial neural network. ISRN Forestry, v. 2013, p. 1-12, 2013.

Curtis, R. Height-diameter and height-diameter-age equations for second-growth Douglas-fir. Forest Science, v. 13, n. 4, p. 365-375, 1967. 
Diamantopoulou, M. J. Artificial neural networks as an alternative tool in pine bark volume estimation. Computers and Electronics in Agriculture, v. 10, p. 235-244, $2005 \mathrm{a}$.

Diamantopoulou, M. J. \& Milios, E. Modelling total volume of dominant pine trees in reforestations via multivariate analysis and artificial neural network models. Biosystems Engineering, v. 105, p. 306-315, 2010.

Diamantopoulou, M. J. Predicting fir trees stem diameters using artificial neural network models. Southern African Forestry Journal, v. 205, n. 1, p. 39-44, 2005 b.

Diamantopoulou, M. J. Tree-Bole volume estimation on standing pine trees using cascade correlation artificial neural network models. Agricultural Engineering International: The CIGR EJournal, v. 8, 2006.

Goldschmidt, R. R. \& Passos, E. Data mining: um guia prático. Rio de Janeiro: Campos, 2005. 261 p.

Görgens, E. B. et al. Estimação do volume de árvores utilizando redes neurais artificiais. Revista Árvore, v. 33, n. 6, p. 1141-1147, 2009.

Görgens, E. B. et al. Influência da arquitetura na estimativa de volume de árvores individuais por meio de redes neurais artificiais. Revista Árvore, v. 38, n. 2, p. 289-295, 2014.

Guan, B. T. \& Gertner, G. Z. Modeling red pine tree survival with an artificial neural network. Forest Science, v. 37, n. 5, p. 1429-1440, 1991.

Haykin, S. Redes neurais: princípios e prática. Porto Alegre, 2001. $900 \mathrm{p}$.
Heaton, J. Programming neural networks with Encog3 in Java. 2nd ed. St. Louis: Heaton Research, 2011. 226 p.

Husch, B. et al. Forest mensuration. New York: John Wiley \& Sons, 2003. $443 \mathrm{p}$.

Leduc, D. J. et al. Predicting diameter distributions of longleaf pine plantations. Asheville: U.S. Deptartment of Agriculture, Forest Service, Southern Research Station, 2001. 24 p. Disponível em: $<$ http://www.treesearch.fs.fed.us/pubs/2819>. Acesso em: 31 out. 2015.

Leite, H. G. \& Andrade, V. C. L. Uso do método da altura relativa em inventário florestal de um povoamento de Pinus. Revista Árvore, v. 28, n. 6, p. 865-873, 2004. DOI: 10.1590/S010067622004000600011 .

Leite, H. G. et al. Estimation of inside-bark diameter and heartwood diameter for Tectona grandis Linn. trees using artificial neural networks. European Journal of Forest Research, v. 130, n. 2, p. 263-269, 2011. DOI: 10.1007/s10342-010-0427-7.

Prodan, M. Forest biometrics. Oxford: Pergamon, 1968. 447 p.

Silva, M. L. M. et al. Ajuste do modelo de Schumacher e Hall e aplicações de redes neurais artificiais para estimar volume de árvores de Eucalipto. Revista Árvore, v. 33, n. 6, p. 1133-1139, 2009.

Vieira, G. C. Prognose do diâmetro e da altura de árvores individuais utilizando inteligência artificial. 2015. 51 f. Dissertação (Mestrado em Ciências Florestais) - Universidade Federal do Espírito Santo, Jerônimo Monteiro. 
